\title{
To fractionate or not to fractionate? That is the question for the radiosurgery of hypoxic tumors
}

\author{
Laboratory investigation
}

\author{
Iuliana Toma-Dasu, Ph.D., ${ }^{1}$ Helena Sandström, M.Sc., ${ }^{1}$ Pierre Barsoum, M.Sc., ${ }^{2}$ \\ and Alexandru Dasu, Ph.D. ${ }^{3}$ \\ ${ }^{I}$ Medical Radiation Physics, Stockholm University and Karolinska Institutet; ${ }^{2}$ Department of Medical \\ Physics, Karolinska University Hospital, Stockholm; and ${ }^{3}$ Departments of Radiation Physics and Medical \\ and Health Sciences, Linköping University, Linköping, Sweden
}

\begin{abstract}
Object. This study aimed to investigate the impact of tumor hypoxia on treatment outcome for metastases commonly treated with radiosurgery using 1 fraction of radiation and the potential gain from reoxygenation if the treatment is delivered in a few radiation fractions.

Methods. In silico metastasis-like radiosurgery targets were modeled with respect to size, density of clonogenic cells, and oxygenation. Treatment plans were produced for the targets using Leksell GammaPlan, delivering clinically relevant doses and evaluating the tumor control probability (TCP) that could be expected in each case. Fractionated schedules with 3,4 , and 5 fractions resulting in similar biological effective doses were also considered for the larger target, and TCP was determined under the assumption that local reoxygenation takes place between fractions.

Results. The results showed that well-oxygenated small- and medium-size metastases are well controlled by radiosurgery treatments delivering 20 or 22 Gy at the periphery, with TCPs ranging from $90 \%$ to $100 \%$. If they are moderately hypoxic, the TCP could decrease to $60 \%$. For large metastases, the TCPs from single-fraction treatments ranged from $0 \%$ to $19 \%$, depending on tumor oxygenation. However, for fractionated treatments, the TCP for hypoxic tumors could significantly increase up to $51 \%$, if reoxygenation occurs between fractions.

Conclusions. This study shows that hypoxia worsens the response to single-fraction radiosurgery, especially for large tumors. However, fractionated therapy for large hypoxic tumors might considerably improve the TCP and might constitute a simple way to improve the outcome of radiosurgery for patients with hypoxic tumors. (http://thejns.org/doi/abs/10.3171/2014.8.GKS141461)
\end{abstract}

\section{Key Words • radiosurgery • metastases • tumor hypoxia • fractionation - stereotactic radiosurgery}

$\mathrm{D}$ ELIVERING a highly conformal dose distribution to the target while sparing the normal tissues surrounding it is one of the central principles of stereotactic radiosurgery. Nevertheless, the distribution of the dose to the tissue is determined by the physics of radiation interaction with the matter and the technological characteristics of the radiation delivery system. Consequently, the dose to the target is often dictated by the tolerance of the normal tissue. Furthermore, the inverse correlation between the volume of the target and the dose that can be delivered to it usually limits the target sizes that can be irradiated with stereotactic techniques. This correlation also leads to the paradox that larger tumors, presumably containing more cells, are treated with lower doses than are smaller tumors with fewer cells.

The success of stereotactic radiosurgery also depends on clinical and radiobiological factors. Delivering the dose in 1 fraction addresses 2 of the classic Rs of radiobiology,

Abbreviations used in this paper: $\mathrm{BED}=$ biological effective dose $; \mathrm{HF}=$ hypoxic fraction; $\mathrm{HI}=$ heterogeneity index; $\mathrm{TCP}=$ tumor control probability. repair and repopulation: delivering a single fraction will not allow time for the tumor to repair sublethal damage or to proliferate and thus to increase the target population through repopulation. Given the sizes of the doses usually delivered, redistribution will not likely influence the outcome. However, oxygenation status of the tumors to be treated will likely influence the outcome, and treatments employing 1 or very few fractions are less influenced by reoxygenation. Indeed, delivering the dose in 1 or a few fractions, as in stereotactic body radiation therapy, prevents slow reoxygenation caused by preferentially killing the well-oxygenated cells at the periphery of the tumor and thus decreasing oxygen consumption and making oxygen available to the hypoxic cells located in the core of the tumor, as described by Thomlinson and Gray. ${ }^{36}$ However, short-term local reoxygenation due to opening of temporarily closed blood vessels, as initially postulated by Brown ${ }^{5}$ and later demonstrated by Chaplin et al., ${ }^{9}$ a process independent of radiation delivery, could change cellular radiosensitivity during multifraction delivery. This study aimed to explore the impact of tumor hypoxia on the outcome of radiosurgery to treat metastases and the potential of fast 
reoxygenation to improve the results of fractionated dose delivery for this type of treatment.

\section{Methods}

The impact of hypoxia and reoxygenation was studied with in silico tumor models with heterogeneous oxygenations. Three sizes of radiosurgery targets were assumed: 1,2 , and $3 \mathrm{~cm}$ in diameter. Also, 3 possible oxygenation states were assumed for the tumors (Fig. 1). They could be well oxygenated, or in the case of larger tumors, they could have a moderately hypoxic or a more hypoxic core. The oxygen distributions calculated for each region accounted for relevant distributions of intervessel distances and the physical processes of oxygen diffusion and consumption, as extensively described in previous publications. ${ }^{10,11}$ The density of clonogenic cells was assumed to be a uniform $10^{6}$ cells $/ \mathrm{cm}^{3}$ throughout the tumors.

For each target, a plan was made in the Leksell GammaPlan version 10.1.1 (Elekta AB) with the 50\% isodose covering the target (Fig. 2). The dose prescription in each plan was target size dependent, with 22 Gy to the $50 \%$ isodose for the 1-cm target and $20 \mathrm{~Gy}$ and $18 \mathrm{~Gy}$ to the 2-cm and 3-cm targets, respectively (Fig. 3). Table 1 lists other dosimetric parameters of interest for each plan, including the gradient index, ${ }^{31}$ the Paddick conformity index, ${ }^{30,41}$ and the heterogeneity index HI:

$$
H I=\frac{D_{\text {max }}-D_{\min }}{D_{\text {mean }}},
$$

where $D_{\max }$ is the maximum dose, $D_{\min }$ is the minimum dose, and $D_{\text {mean }}$ is the mean dose to the target volume.
Tumor response was assessed as tumor control probability (TCP), calculated as

$$
T C P=\exp \left\{-\sum_{i=1}^{N_{\text {vox }}} N_{i}\left[S F\left(d_{i}, p_{i}\right)\right]\right\},
$$

where $N_{\text {vox }}$ is the number of calculation voxels in the tumor, $N_{i}$ is the number of cells in voxel $i$, and $\operatorname{SF}\left(d_{i}, p_{i}\right)$ is the cell survival in voxel $i$ dependent on dose $d_{i}$ and oxygen tension $p_{i}$. Cell survival was calculated with the linear quadratic model, ${ }^{7,16}$ using the formalism described in Toma-Dasu and Dasu. ${ }^{38}$ Thus, cell survival $\mathrm{SF}_{i}$ in each voxel receiving dose $d_{i}$ is described by

$$
S F\left(d_{i}, p_{i}\right)=\exp \left[-\frac{\alpha}{O M F\left(p_{i}\right)} d_{i}-\frac{\beta}{O M F^{2}\left(p_{i}\right)} d_{i}^{2}\right],
$$

where $\alpha$ and $\beta$ are the linear quadratic parameters relevant for oxic cells and $\mathrm{OMF}\left(p_{i}\right)$ are oxygen tension-dependent modification factors:

$$
O M F\left(p_{i}\right)=O E R_{\max } \frac{k+p_{i}}{k+O E R_{\max } p_{i}},
$$

where $\mathrm{OER}_{\text {max }}$ is the maximum protection achieved in the absence of oxygen and $k$ is a reaction constant as described by Alper and Howard-Flanders. ${ }^{1}$ The following oxic parameters were assumed for calculation ${ }^{17}: \alpha=0.35$ $\mathrm{Gy}^{-1}$ and $\alpha / \beta=10 \mathrm{~Gy}$.

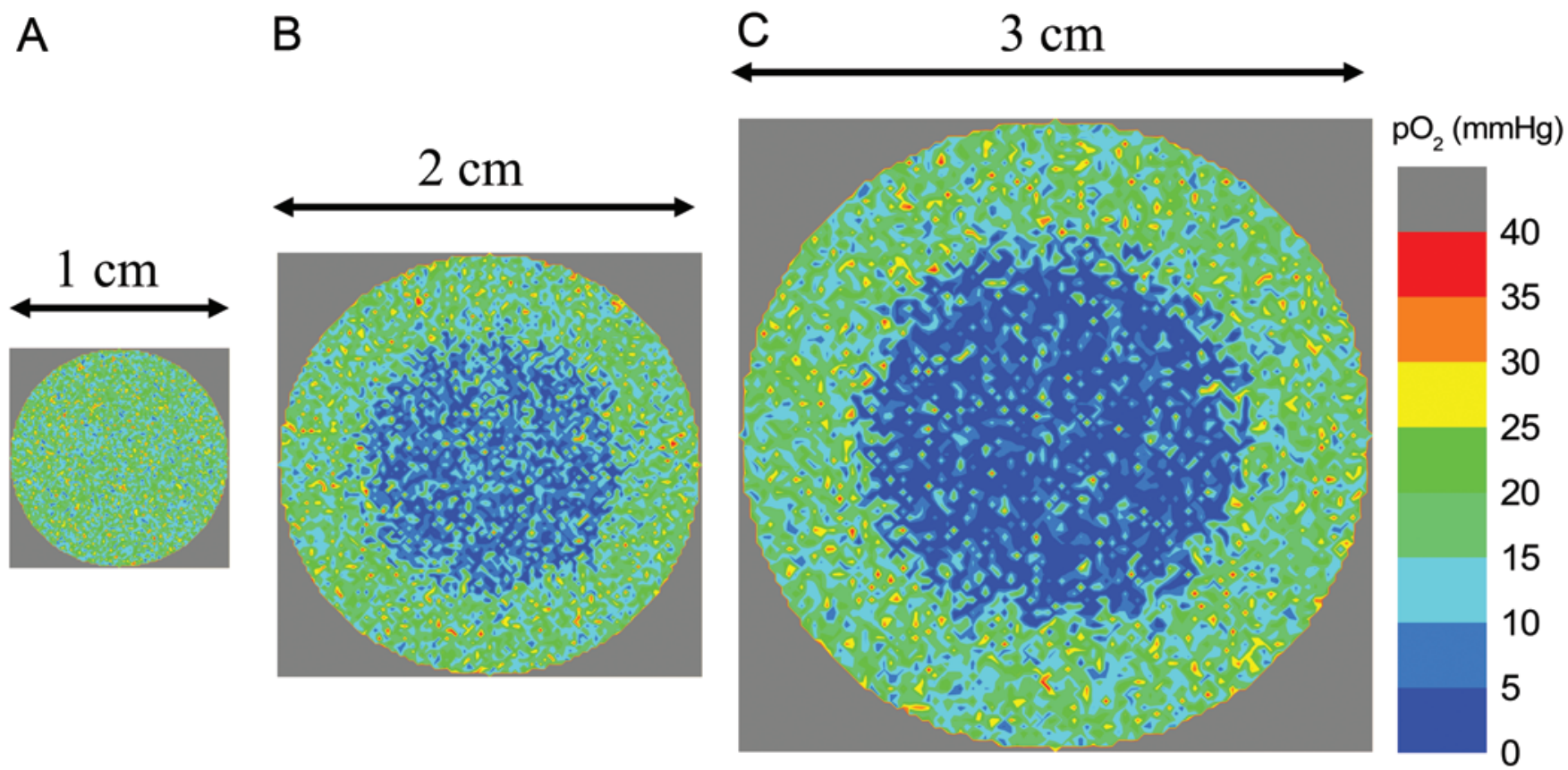

FIG. 1. Sections through the central plane of tumor models used in the study, showing examples of the different oxygenation states considered. A: A well-oxygenated small tumor, $1 \mathrm{~cm}$ in diameter $\left(0.52 \mathrm{~cm}^{3}\right.$ volume); the $\mathrm{HF}$, calculated as the percentage of values with $\mathrm{pO}_{2}<5 \mathrm{~mm} \mathrm{Hg}$, is $0 \%$. B: A moderately hypoxic ( $\left.\mathrm{HF}=4 \%\right)$ medium-size tumor, $2 \mathrm{~cm}$ in diameter $\left(4.19 \mathrm{~cm}^{3}\right.$ volume). C: A hypoxic ( $\mathrm{HF}=10 \%$ ) large-size tumor, $3 \mathrm{~cm}$ in diameter $\left(14.14 \mathrm{~cm}^{3}\right.$ volume). 
A

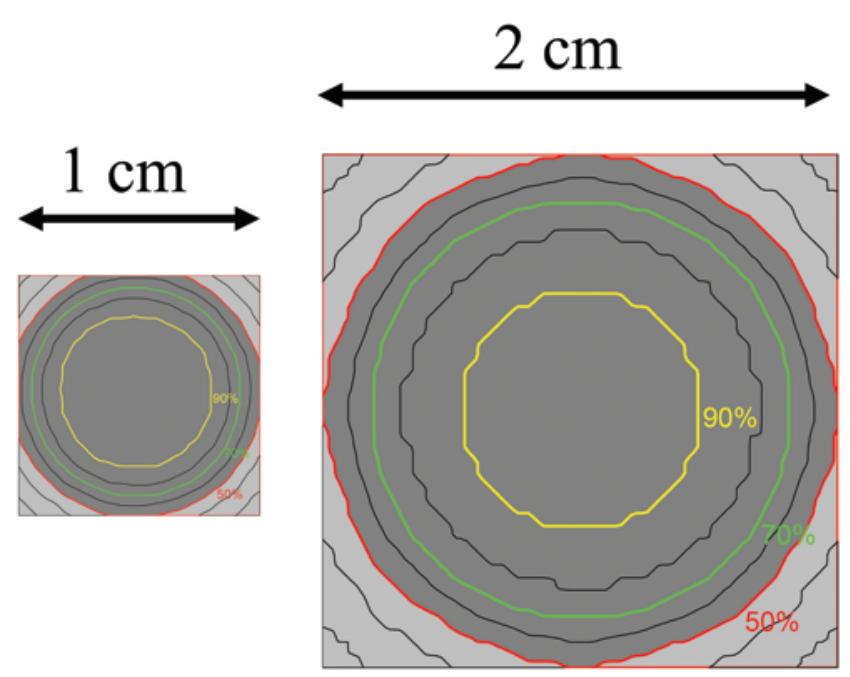

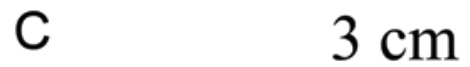

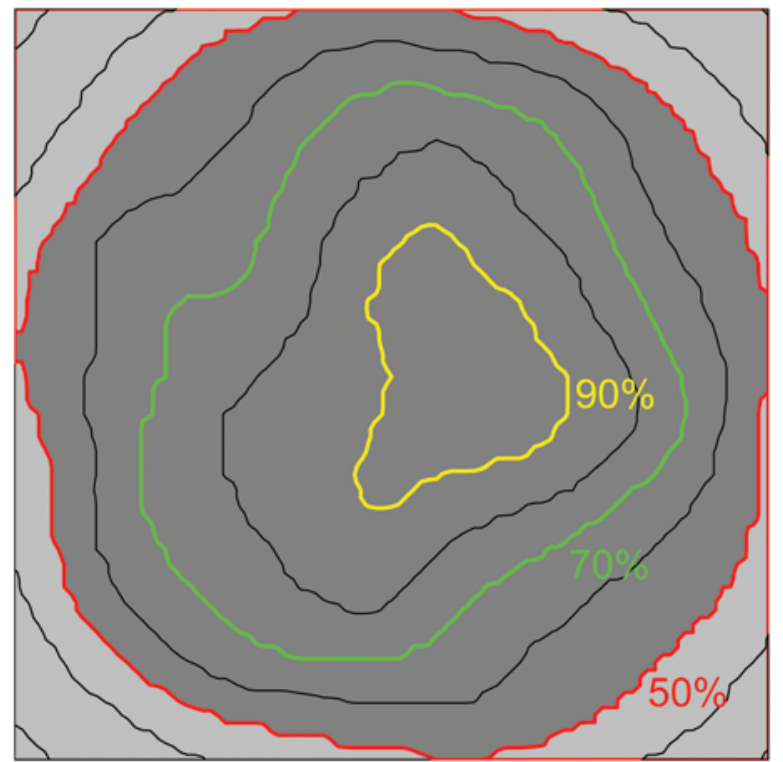

FIG. 2. Dose distributions in the central plane for each target size illustrated in Fig. 1, with the $50 \%$ isodose covering the target.

Fractionated schedules with 3, 4, and 5 fractions leading to the same biological effective doses (BEDs) to the tumor $^{3}$ (i.e., for $\alpha / \beta=10 \mathrm{~Gy}$ ) were also considered for the larger target (Table 2). In this case, TCP was calculated assuming that fast local reoxygenation takes place between fractions.

\section{Results}

The simulations showed that well-oxygenated smalland medium-size metastases could be very well controlled by radiosurgery treatments delivering a single fraction of 20 Gy or 22 Gy at the periphery, with TCPs ranging from $90 \%$ to $100 \%$. However, for moderately hypoxic tumors, the TCP would decrease to $60 \%$. In contrast, large metastases were difficult to control with single-fraction regimes, with TCPs ranging from $0 \%$ to $19 \%$, depending on the assumed oxygenation state. Thus, it appears that hypoxia worsens the response to single-fraction radiosurgery, especially for large tumors.
With fractionated treatments for hypoxic tumors, interfraction reoxygenation resulted in significantly increased TCPs, up to 51\% (Table 3). Better results are obtained for oxic and even moderately hypoxic tumors, but even large, severely hypoxic tumors could be controlled with fractionated regimes. Furthermore, for the latter the TCP increases with the number of fractions, highlighting the importance of the number of opportunities for reoxygenation to improve the possible outcome. These results therefore emphasize the importance of using pretreatment tumor oxygenation status to choose the best treatment option for radiosurgery patients.

\section{Discussion}

Tumor hypoxia is an important determinant of outcome in radiation therapy, as the absence of oxygen could render the cells resistant to radiation and could also contribute to the selection of more aggressive tumor cell phenotypes. ${ }^{42}$ Several proposals have been made to
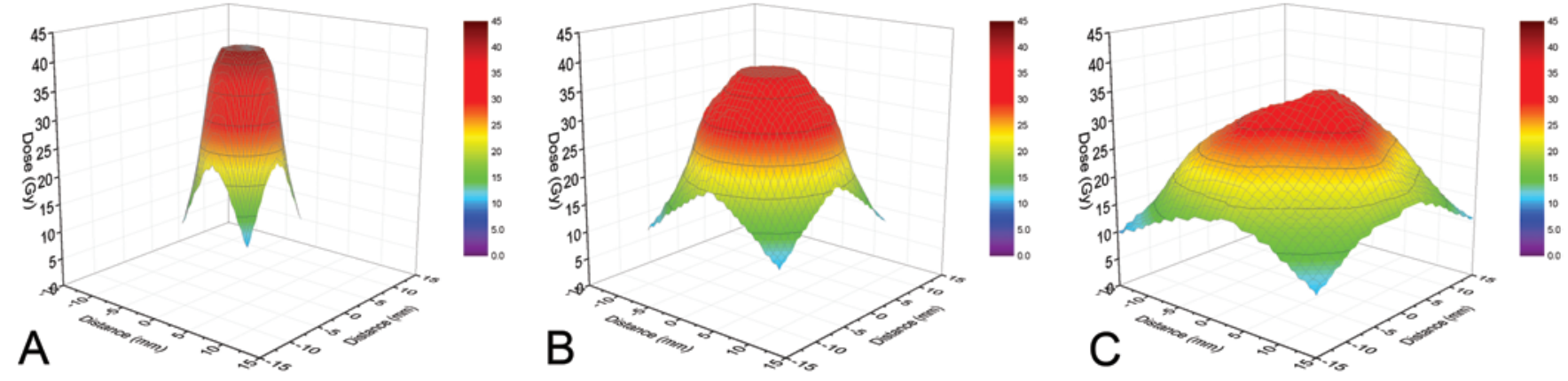

FIG. 3. Dose distributions in the central plane for each target size illustrated in Fig. 1, with 22 Gy to the $50 \%$ isodose for the 1-cm target (A), 20 Gy for the 2-cm target (B), and 18 Gy for the 3-cm target (C). 
TABLE 1: Treatment plan dosimetric parameters for the targets considered in this study

\begin{tabular}{lccc}
\hline \multicolumn{1}{c}{ Parameter } & $\begin{array}{c}10-\mathrm{mm} \\
\text { Target }\end{array}$ & $\begin{array}{c}20-\mathrm{mm} \\
\text { Target }\end{array}$ & $\begin{array}{c}30-\mathrm{mm} \\
\text { Target }\end{array}$ \\
\hline 4-mm shots & 3 & 0 & 0 \\
8-mm shots & 1 & 3 & 14 \\
16-mm shots & 0 & 1 & 9 \\
composite shots & 0 & 0 & 0 \\
grid size (mm) & 0.7 & 1.2 & 1.6 \\
coverage & $99 \%$ & $99 \%$ & $98 \%$ \\
selectivity & $92 \%$ & $97 \%$ & $97 \%$ \\
gradient index & 3.20 & 2.56 & 2.70 \\
Paddick conformity index & 0.91 & 0.96 & 0.95 \\
HI & 0.72 & 0.82 & 0.87 \\
\hline
\end{tabular}

counteract the hypoxic cells in conventional radiotherapy, although they have been slow to enter clinical practice. ${ }^{29}$ The most recent proposals for antihypoxic strategies aiming to increase the doses to the hypoxic foci in tumors are quite promising, and several studies have been initiated to investigate their clinical potential. . $^{37,39,40}$

Hypoxia is not usually taken into account for stereotactic radiosurgery, in part because of the large doses that could be delivered to the target while keeping irradiation of normal tissues within tolerances. Nevertheless, the results of this study show that hypoxia could negatively affect the results from single-fraction stereotactic radiosurgery, especially for larger tumors, for which normal tissue imposes limitations on the maximum dose that can be delivered to the target. Given that the options available for patients with large inoperable cranial tumors are usually limited to palliative treatments or treatments with conventional fractionations, it is worthwhile to explore whether they could benefit from stereotactic radiation treatments. The present study shows that allowing local reoxygenation of the tumors by fractionating the treatment could significantly improve the outcome for patients with large tumors by taking advantage of the favorable dose distributions that could be delivered with radiosurgery techniques.

These results were obtained under the constraint that the fractionated treatments deliver the same BEDs to the edge of the target. The corresponding effect to the normal brain decreases with increasing fractionation, as shown in the last column in Table 2 , due to the lower values of $\alpha / \beta$

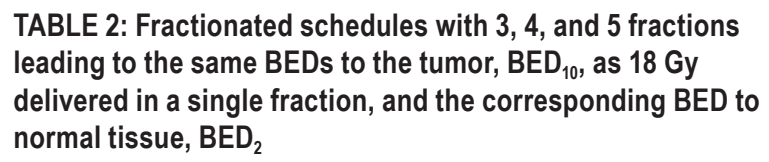

TABLE 2: Fractionated schedules with 3, 4, and 5 fractions leading to the same BEDs to the tumor, $\mathrm{BED}_{10}$, as $18 \mathrm{~Gy}$ delivered in a single fraction, and the corresponding BED to normal tissue, $\mathrm{BED}_{2}$

\begin{tabular}{ccccc}
\hline $\begin{array}{c}\text { Total Dose } \\
D(\mathrm{~Gy})\end{array}$ & $\begin{array}{c}\text { Dose per } \\
\text { Fraction d (Gy) }\end{array}$ & $\begin{array}{c}\text { No. of } \\
\text { Fractions } n\end{array}$ & $\begin{array}{c}\mathrm{BED}_{10} \\
\left(\mathrm{~Gy}_{10}\right)\end{array}$ & $\begin{array}{c}\mathrm{BED}_{2} \\
\left(\mathrm{~Gy}_{2}\right)\end{array}$ \\
\hline 18.0 & 18.0 & 1 & 50.4 & 180.0 \\
26.7 & 8.9 & 3 & 50.4 & 145.3 \\
29.2 & 7.3 & 4 & 50.4 & 135.4 \\
31.1 & 6.2 & 5 & 50.4 & 127.7 \\
\hline
\end{tabular}

TABLE 3: Tumor control probabilities for a large tumor under 2 oxygenation conditions*

\begin{tabular}{cccc}
\hline \multirow{2}{*}{$\begin{array}{c}\text { Total Dose } D \\
(\mathrm{~Gy})\end{array}$} & $\begin{array}{c}\text { No. of } \\
\text { Fractions } n\end{array}$ & $\begin{array}{c}\text { Moderately Hypoxic } \\
(\mathrm{HF}=4 \%)\end{array}$ & $\begin{array}{c}\text { Hypoxic } \\
(\mathrm{HF}=10 \%)\end{array}$ \\
\hline 18.0 & 1 & $0 \%$ & $0 \%$ \\
26.7 & 3 & $46 \%$ & $11 \%$ \\
29.2 & 4 & $51 \%$ & $35 \%$ \\
31.1 & 5 & $51 \%$ & $43 \%$ \\
\hline * For the treatment schedules using $\geq 1$ fraction, TCP was calculated
\end{tabular}

for this tissue. This has 2 important implications for maximizing tumor control and minimizing complications in normal tissues: 1) fewer side effects are expected with the same effect to the tumor, which is especially important for larger targets, for which a lower dose gradient can be achieved, with a higher radiation burden on the normal tissue compared with smaller targets; and 2) further improvements in tumor response could be obtained by escalating the delivered dose within the limit of the normal tissue tolerance. Indeed, the most fractionated regimen assumed in this study was 31.1 Gy in 5 fractions; similar stereotactic regimes delivered using linear accelerators may employ 40 Gy in 5 fractions.

Our results were obtained from theoretical simulations and may therefore be influenced by the inherent limitations of the method. The simulations focused on the direct effect of radiation on the tumor cells, whereas other mechanisms may also be involved in cell death. For example, the immune system may be responsible for removing a few logs of cells. ${ }^{14}$ Although accurate numbers are not available for this process, it was partly included in our simulation by assuming a low density of clonogens per unit volume. Furthermore, tumor cells depend on the supply of nutrients through the vascular network. Tumor vasculature, although not directly associated with radiosurgery, has long been considered a possible target to increase cell death. ${ }^{12,13}$ A high-dose fraction in the range of 8-11 Gy may induce endothelial apoptosis of the tumor vasculature, thus indirectly increasing cell death by abolishing nutrient supply, ${ }^{35}$ much like vascular targeting. This effect is in addition to direct cell death by radiation, and it could increase the TCPs above those given in Table 3 , as suggested by Park et al. ${ }^{32}$ The additional effect of vasculature damage could decrease with increased fractionation, because the fractional dose is lower than the threshold for inducing vascular effects. Nevertheless, the effect of vascular damage changes the baseline TCP values for extremely hypofractionated schedules, and hypoxia could be regarded as an additional factor able to modulate response to radiation therapy. In this respect, the results of this study also agree with those of Carlson et al., ${ }^{6}$ who showed that extreme hypofractionation should be avoided for hypoxic tumors because reoxygenation possibilities are severely reduced during the treatment course.

Another possibility that was not included in this simulation was that cellular density might vary with tumor 
oxygenation. Severely hypoxic tumors could have fewer viable cells toward their center, as necrosis would set in. In this case, an increased dose to the center would be delivered to a sparsely populated region of the tumor. From this perspective, the models in this study and TCP results should be regarded as worst-case scenarios regarding the impact of hypoxia and improvements that could be obtained in clinical settings. Nevertheless, this study shows the significant improvements that could be obtained through fractionation even for the most unfavorable intratumor cell distributions (Table 3).

Finally, the validity of the linear quadratic model for the large doses employed in radiosurgery is an ongoing debate. ${ }^{4,18,24,34}$ However, the present study focused on the response of mixed cell populations containing a large hypoxic subpopulation for which the linear quadratic model is able to accurately describe the response, ${ }^{25}$ so the results should be relevant for clinically used dose prescriptions to cranial targets treated with stereotactic radiosurgery.

An important question is whether predictions from theoretical simulations are compatible with clinical experience. Several analyses show that local control for single-fraction radiosurgery decreases when the dose delivered to the tumor margin decreases or when tumor size increases..$^{8,19,20,27,43}$ Furthermore, the results reported by these analyses are compatible with the theoretical TCP results in the present study; vascular and immunologic effects are probably responsible for any differences. Chang et al. ${ }^{8}$ reported local control rates at 1 and 2 years, respectively, of $86 \%$ and $78 \%$ for lesions $<1 \mathrm{~cm}$, and $56 \%$ and $24 \%$ for lesions $>1 \mathrm{~cm}$, treated with a minimum peripheral dose of $20 \mathrm{~Gy}\left(\mathrm{BED}_{10}=60 \mathrm{~Gy}_{10}\right)$. Similarly, Hasegawa et al. ${ }^{20}$ reported local control rates of $84 \%$ and $77 \%$, respectively, for tumors $<4 \mathrm{~cm}^{3}(\sim 2 \mathrm{~cm}$ equivalent diameter) at 1 and 2 years after treatment with a mean marginal dose of $18.5 \mathrm{~Gy}\left(\mathrm{BED}_{10}=52.7 \mathrm{~Gy}_{10}\right)$. Vogelbaum et al. ${ }^{43}$ reported 1-year control rates of $85 \%$ in tumors < $2 \mathrm{~cm}$ treated with $24 \mathrm{~Gy}\left(\mathrm{BED}_{10}=81.6 \mathrm{~Gy}_{10}\right), 49 \%$ in tumors of $2-3 \mathrm{~cm}$ treated with $18 \mathrm{~Gy}\left(\mathrm{BED}_{10}=50.4 \mathrm{~Gy}_{10}\right)$, and $45 \%$ in tumors $>3 \mathrm{~cm}$ treated with 15 Gy $\left(\mathrm{BED}_{10}\right.$ $=37.5\left(\mathrm{~Gy}_{10}\right)$. More recently, Fokas et al. ${ }^{15}$ reported $73 \%$ local control at 1 year after 20 Gy in 138 patients with tumors with a median diameter of $1.5 \mathrm{~cm}$.

In contrast, fractionated radiosurgery appears to lead to improved local control, especially for larger tumors, in line with results of the present study. Aoyama et al. ${ }^{2}$ reported $81 \%$ local control at 1 year in 87 patients with tumors with a median equivalent diameter of $1.8 \mathrm{~cm}$ treated with a median dose of $35 \mathrm{~Gy}$ in 4 fractions $\left(\mathrm{BED}_{10}=65.6 \mathrm{~Gy}_{10}\right)$. Narayana et al. ${ }^{28}$ reported $70 \%$ local control at 1 year after $30 \mathrm{~Gy}$ in 5 fractions $\left(\mathrm{BED}_{10}=48 \mathrm{~Gy}_{10}\right)$ in 20 patients with $1.9-\mathrm{cm}$ tumors. Higuchi et al. ${ }^{21}$ analyzed 43 patients with tumors $>3 \mathrm{~cm}$ and reported $76 \%$ local control at 1 year after 30 Gy in 3 fractions $\left(\mathrm{BED}_{10}=60 \mathrm{~Gy}_{10}\right)$. Fokas et al. ${ }^{15}$ reported 1-year local control rates of 75\% and 71\% in 122 patients treated either with 35 Gy in 7 fractions $\left(\mathrm{BED}_{10}=\right.$ $52.5 \mathrm{~Gy}_{10}$ ) for tumors of about $1.6 \mathrm{~cm}$ or with $40 \mathrm{~Gy}$ in 10 fractions $\left(\mathrm{BED}_{10}=56 \mathrm{~Gy}_{10}\right)$ for tumors of about $2.2 \mathrm{~cm}$, respectively. Rajakesari et al. ${ }^{33}$ reported $56 \%$ local control at 1 year in 70 patients with a median tumor diameter of 1.7 $\mathrm{cm}$ treated mainly with 25 Gy in 5 fractions $\left(\mathrm{BED}_{10}=37.5\right.$
$\mathrm{Gy}_{10}$ ). Minniti et al. ${ }^{26}$ reported 1- and 2-year local control rates of $88 \%$ and $75 \%$, respectively, for 135 patients treated with 36 Gy in 3 fractions $\left(\mathrm{BED}_{10}=79.2 \mathrm{~Gy}_{10}\right)$ for tumors $<2 \mathrm{~cm}$ and with $27 \mathrm{~Gy}$ in 3 fractions $\left(\mathrm{BED}_{10}=51.3 \mathrm{~Gy}_{10}\right)$ for tumors $>2 \mathrm{~cm}$. Fractionated treatments also appear to lead to lower toxicity rates than single-fraction treatments, ${ }^{15,22,23,26}$ also in line with the proposals of the present study. Although only a randomized trial will show whether fractionated radiosurgery may improve the outcome of larger tumors with less toxicity, this in silico analysis nevertheless appears to support this hypothesis. Further theoretical and practical exploration of the potential of fractionated stereotactic radiosurgery is therefore warranted.

\section{Conclusions}

This study showed that hypoxia worsens the response to single-fraction radiosurgery, especially for large tumors. Fractionated therapy for large hypoxic tumors might considerably improve the TCP. These results therefore suggest that determining pretreatment tumor oxygenation status and considering fractionation for the patients with hypoxic tumors might improve the outcome of radiosurgery. This may be a practical and relatively simple way to individualize treatment for radiosurgery patients.

\section{Disclosure}

Financial support from the Cancer Research Funds of Radiumhemmet, Linköping University, and the County Council of Östergötland is gratefully acknowledged. The authors report no conflict of interest concerning the materials or methods used in this study or the findings in this paper.

Author contributions to the study and manuscript preparation include the following. Conception and design: Toma-Dasu, Dasu. Acquisition of data: Sandström, Barsoum. Analysis and interpretation of data: all authors. Drafting the article: Toma-Dasu, Dasu. Critically revising the article: all authors. Reviewed submitted version of manuscript: all authors. Approved the final version of the manuscript on behalf of all authors: Toma-Dasu.

\section{References}

1. Alper T, Howard-Flanders P: Role of oxygen in modifying the radiosensitivity of E. coli B. Nature 178:978-979, 1956

2. Aoyama H, Shirato H, Onimaru R, Kagei K, Ikeda J, Ishii N, et al: Hypofractionated stereotactic radiotherapy alone without whole-brain irradiation for patients with solitary and oligo brain metastasis using noninvasive fixation of the skull. Int J Radiat Oncol Biol Phys 56:793-800, 2003

3. Barendsen GW: Dose fractionation, dose rate and iso-effect relationships for normal tissue responses. Int J Radiat Oncol Biol Phys 8:1981-1997, 1982

4. Brenner DJ: The linear-quadratic model is an appropriate methodology for determining isoeffective doses at large doses per fraction. Semin Radiat Oncol 18:234-239, 2008

5. Brown JM: Evidence for acutely hypoxic cells in mouse tumours, and a possible mechanism of reoxygenation. Br J Radiol 52:650-656, 1979

6. Carlson DJ, Keall PJ, Loo BW Jr, Chen ZJ, Brown JM: Hypofractionation results in reduced tumor cell kill compared to conventional fractionation for tumors with regions of hypoxia. Int J Radiat Oncol Biol Phys 79:1188-1195, 2011

7. Chadwick KH, Leenhouts HP: A molecular theory of cell survival. Phys Med Biol 18:78-87, 1973 
8. Chang EL, Hassenbusch SJ III, Shiu AS, Lang FF, Allen PK, Sawaya $R$, et al: The role of tumor size in the radiosurgical management of patients with ambiguous brain metastases. Neurosurgery 53:272-281, 2003

9. Chaplin DJ, Durand RE, Olive PL: Acute hypoxia in tumors: implications for modifiers of radiation effects. Int J Radiat Oncol Biol Phys 12:1279-1282, 1986

10. Daşu A, Toma-Daşu I: Vascular oxygen content and the tissue oxygenation-a theoretical analysis. Med Phys 35:539-545, 2008

11. Daşu A, Toma-Daşu I, Karlsson M: Theoretical simulation of tumour oxygenation and results from acute and chronic hypoxia. Phys Med Biol 48:2829-2842, 2003

12. Denekamp J: Vascular endothelium as the vulnerable element in tumours. Acta Radiol Oncol 23:217-225, 1984

13. Denekamp J, Daşu A, Waites A: Vasculature and microenvironmental gradients: the missing links in novel approaches to cancer therapy? Adv Enzyme Regul 38:281-299, 1998

14. Finkelstein SE, Timmerman R, McBride WH, Schaue D, Hoffe SE, Mantz CA, et al: The confluence of stereotactic ablative radiotherapy and tumor immunology. Clin Dev Immunol 2011:439752, 2011

15. Fokas E, Henzel M, Surber G, Kleinert G, Hamm K, Engenhart-Cabillic R: Stereotactic radiosurgery and fractionated stereotactic radiotherapy: comparison of efficacy and toxicity in 260 patients with brain metastases. J Neurooncol 109:9198, 2012

16. Fowler JF: The linear-quadratic formula and progress in fractionated radiotherapy. Br J Radiol 62:679-694, 1989

17. Fowler JF: Sensitivity analysis of parameters in linear-quadratic radiobiologic modeling. Int J Radiat Oncol Biol Phys 73:1532-1537, 2009

18. Guckenberger M, Klement RJ, Allgäuer M, Appold S, Dieckmann K, Ernst I, et al: Applicability of the linear-quadratic formalism for modeling local tumor control probability in high dose per fraction stereotactic body radiotherapy for early stage non-small cell lung cancer. Radiother Oncol 109:1320,2013

19. Han JH, Kim DG, Chung HT, Paek SH, Park CK, Jung HW: Radiosurgery for large brain metastases. Int J Radiat Oncol Biol Phys 83:113-120, 2012

20. Hasegawa T, Kondziolka D, Flickinger JC, Germanwala A, Lunsford LD: Brain metastases treated with radiosurgery alone: an alternative to whole brain radiotherapy? Neurosurgery 52:1318-1326, 2003

21. Higuchi Y, Serizawa T, Nagano O, Matsuda S, Ono J, Sato M, et al: Three-staged stereotactic radiotherapy without whole brain irradiation for large metastatic brain tumors. Int J Radiat Oncol Biol Phys 74:1543-1548, 2009

22. Kaul D, Budach V, Wurm R, Gruen A, Graaf L, Habbel P, et al: Linac-based stereotactic radiotherapy and radiosurgery in patients with meningioma. Radiat Oncol 9:78, 2014

23. Kim YJ, Cho KH, Kim JY, Lim YK, Min HS, Lee SH, et al: Single-dose versus fractionated stereotactic radiotherapy for brain metastases. Int J Radiat Oncol Biol Phys 81:483-489, 2011

24. Kirkpatrick JP, Meyer JJ, Marks LB: The linear-quadratic model is inappropriate to model high dose per fraction effects in radiosurgery. Semin Radiat Oncol 18:240-243, 2008

25. Lindblom E, Dasu A, Lax I, Toma-Dasu I: Survival and tumour control probability in tumours with heterogeneous oxygenation: a comparison between the linear-quadratic and the universal survival curve models for high doses. Acta Oncol 53:1035-1040, 2014

26. Minniti G, D'Angelillo RM, Scaringi C, Trodella LE, Clarke E, Matteucci $P$, et al: Fractionated stereotactic radiosurgery for patients with brain metastases. J Neurooncol 117:295-301, 2014

27. Molenaar R, Wiggenraad R, Verbeek-de Kanter A, Walchenbach R, Vecht C: Relationship between volume, dose and local control in stereotactic radiosurgery of brain metastasis. Br $\mathbf{J}$ Neurosurg 23:170-178, 2009

28. Narayana A, Chang J, Yenice K, Chan K, Lymberis S, Brennan $\mathrm{C}$, et al: Hypofractionated stereotactic radiotherapy using intensity-modulated radiotherapy in patients with one or two brain metastases. Stereotact Funct Neurosurg 85:82-87, 2007

29. Overgaard J: Hypoxic radiosensitization: adored and ignored. J Clin Oncol 25:4066-4074, 2007

30. Paddick I: A simple scoring ratio to index the conformity of radiosurgical treatment plans. Technical note. J Neurosurg 93 Suppl 3:219-222, 2000

31. Paddick I, Lippitz B: A simple dose gradient measurement tool to complement the conformity index. J Neurosurg 105 Suppl:194-201, 2006

32. Park HJ, Griffin RJ, Hui S, Levitt SH, Song CW: Radiationinduced vascular damage in tumors: implications of vascular damage in ablative hypofractionated radiotherapy (SBRT and SRS). Radiat Res 177:311-327, 2012

33. Rajakesari S, Arvold ND, Jimenez RB, Christianson LW, Horvath MC, Claus EB, et al: Local control after fractionated stereotactic radiation therapy for brain metastases. J Neurooncol [epub ahead of print], 2014

34. Song CW, Cho LC, Yuan J, Dusenbery KE, Griffin RJ, Levitt SH: Radiobiology of stereotactic body radiation therapy/stereotactic radiosurgery and the linear-quadratic model. Int $\mathbf{J}$ Radiat Oncol Biol Phys 87:18-19, 2013

35. Song CW, Kim MS, Cho LC, Dusenbery K, Sperduto PW: Radiobiological basis of SBRT and SRS. Int J Clin Oncol 19:570-578, 2014

36. Thomlinson RH, Gray LH: The histological structure of some human lung cancers and the possible implications for radiotherapy. Br J Cancer 9:539-549, 1955

37. Thorwarth D, Mönnich D, Zips D: Methodological aspects on hypoxia PET acquisition and image processing. Q J Nucl Med Mol Imaging 57:235-243, 2013

38. Toma-Dasu I, Dasu A: Modelling tumour oxygenation, reoxygenation and implications on treatment outcome. Comput Math Methods Med 2013:141087, 2013

39. Toma-Daşu I, Daşu A, Brahme A: Dose prescription and optimisation based on tumour hypoxia. Acta Oncol 48:11811192, 2009

40. Toma-Dasu I, Uhrdin J, Antonovic L, Dasu A, Nuyts S, Dirix $\mathrm{P}$, et al: Dose prescription and treatment planning based on FMISO-PET hypoxia. Acta Oncol 51:222-230, 2012

41. van't Riet A, Mak AC, Moerland MA, Elders LH, van der Zee $\mathrm{W}$ : A conformation number to quantify the degree of conformality in brachytherapy and external beam irradiation: application to the prostate. Int J Radiat Oncol Biol Phys 37:731-736, 1997

42. Vaupel P, Mayer A: Hypoxia in cancer: significance and impact on clinical outcome. Cancer Metastasis Rev 26:225239, 2007

43. Vogelbaum MA, Angelov L, Lee SY, Li L, Barnett GH, Suh $\mathrm{JH}$ : Local control of brain metastases by stereotactic radiosurgery in relation to dose to the tumor margin. J Neurosurg 104:907-912, 2006

\section{Manuscript submitted June 30, 2014.}

Accepted August 4, 2014.

Presented in abstract form at the 17th International Leksell Gamma Knife Society Meeting, New York, New York, May 11-15, 2014.

Please include this information when citing this paper: DOI: 10.3171/2014.8.GKS141461.

Address correspondence to: Iuliana Toma-Dasu, Ph.D., Medical Radiation Physics, Karolinska Institutet, Box 260, 17176 Stockholm, Sweden. email: iuliana.livia.dasu@ki.se. 